\section{VEGF and its Receptors in Uterine Cervix: Dose-dependent Modulation by Hypoxia and Estrogen in Mice and Cellular Localization in Human}

\author{
Takako Ohashi ${ }^{1}$, Dilly Anumba ${ }^{3}$ and Chishimba Nathan \\ Mowa $^{1,2 *}$ \\ ${ }^{1}$ Appalachian State University, Boone, North Carolina, USA \\ ${ }^{2}$ University of Johannesburg, Faculty of Health Sciences, Johannesburg, \\ South Africa \\ ${ }^{3}$ Sheffield Medical School, Sheffield, England
}

\begin{abstract}
The uterine cervix undergoes significant changes over the course of pregnancy, including increase in tissue size, pronounced micro vascular remodeling and increase in local Vascular Endothelial Growth Factor (VEGF) and its receptors. These changes are associated with high levels of plasma estrogen. In the present study we examined: a) the effects of mimicked hypoxia $\left(\mathrm{CoCl}_{2}\right)$ and Exogenous Estrogen $\left(E_{2}\right)$ on the expression pattern of VEGF and its Receptors (R), VEGFR-1 (or Flt-1, from henceforth) and -2, and b) the expression pattern of and identity of cell types expressing VEGF and its receptors in mice (pregnant and non-pregnant) and human (non-pregnant) uterine cervices. Our present findings: 1) in mice: a) reveal the cellular pattern of VEGF expression and its receptors (FIt-1 and VEGFR-2); b) and show that hypoxia and $E_{2}$ tend to induce expression of VEGF in the uterine cervix; and 2) in human, demonstrate presence of VEGF and its receptors (Flt-1 and VEGFR-2), in the uterine cervix. We conclude that VEGF and its receptors are altered by hypoxia and $E_{2}$ in a time or dose-dependent manner; synthesized by multiple cell types in mice, and are also present and variably expressed in the human uterine cervix. Collectively, these data shed new insights into the regulation and pattern of VEGF expression in the uterine cervix of rodents and human.
\end{abstract}

*Corresponding author: Chishimba Nathan Mowa, Department of Biology, Appalachian State University, Rankin Science North Building N219 572 River Street, Boone, NC 28608, Tel: +18282622676; Fax: +18282622127; E-mail: mowacn@appstate.edu

Citation: Ohashi T, Anumba D, Mowa CN (2014) VEGF and its Receptors in Uterine Cervix: Dose-dependent Modulation by Hypoxia and Estrogen and Cellular Localization in Human. J Cytol Tissue Biol 1: 006.

Received: August 28, 2014; Accepted: December 05, 2014; Published: December 22, 2014
Keywords: Estrogen; Hypoxia; Uterine cervix; VEGF; VEGF receptors

\section{Introduction}

The uterine cervix undergoes significant changes over the course of pregnancy, including increase in tissue size, pronounced micro vascular remodeling and increase in local Vascular Endothelial Growth Factor (VEGF) and its receptors. These changes are associated with high levels of plasma Estrogen $\left(\mathrm{E}_{2}\right)$ [1]. In the uterus, the local levels of VEGF, the key architect of vascular events in the body, are believed to be regulated by a number of factors, notably the sex steroids, relaxin and hypoxia [2-4]. However, the role of sex steroids and hypoxia in regulating the expression of VEGF and its receptors in the uterine cervix has not been examined.

VEGF belongs to a family of growth factors that are closely related, including VEGF-A, - B, -C, -D, -E and Placenta Growth Factor (PIGF) [5]. VEGF-A or simply VEGF, has effects that are biologically related and exists as several splice variants [5]. These biological effects are largely mediated by two receptors: VEGF receptor-1 (also called fms-like tyrosine kinase-1, or flt-1, from henceforth) and 2 (VEGFR-2) [6,7]. VEGF in female reproductive biology is best known for its roles in the ovarian and uterine events. For instance, VEGF is thought to be essential for a variety of ovarian and uterine endometrial functions that are also associated with $\mathrm{E}_{2}$, notably mediation of cyclical growth of blood vessels. Administration of VEGF inhibitor (mFlt- [8-10] -IgG) essentially blocks corpus luteum angiogenesis and maturation of endometrium [11]. However, until recently very little was known about VEGF's presence and function in the uterine cervix, in general, and Cervical Remodeling (CR), in particular.

We have previously demonstrated the existence and expression profile of VEGF and its key receptors, Flt- and VEGFR-2, in the uterine cervix of rodents (mice and rats); deciphered genes regulated by VEGF in the uterine cervix using DNA microarray analysis [2,12]; and more recently examined VEGF's specific physiological roles in CR, such as cervical epithelial cellular growth immune cell recruitment and migration to the lumen of the uterine cervix and induction of an inflammatory response [13-15]. However, factors and mechanisms that underlie the regulation of VEGF e xpression and its receptors in the uterine cervix have not yet been reported, other than sensory-derived neuropeptides and inflammation-inducing factors $[12,14]$, Outside the uterine cervix, a range of factors and conditions have been identified to influence the expression of VEGF, notably: hypoxia, cytokines [e.g., Interleukin-1 (IL-1), Tumor Necrosis Factor- $\alpha$ (TNF- $\alpha$ )], growth factors (TGF 2 , FGFs, PDGF), advanced glycation end products, vasopressor hormones, relaxin, sex steroid hormones, mechanical stress, and many more [16-19].

Of these factors (cited earlier), the most likely to influence VEGF levels in the uterine cervix may include mechanical stress, sex steroid hormones, hypoxia, relaxin and cytokines, based on the following rationale: a) the growing fetus exerts increasing gravitational pressure 
(mechanical stress) on the uterine cervix [20]; b) a temporal and spatial relationship exists between $\mathrm{E}_{2}$, relaxin, VEGF and their receptors during pregnancy, and $\mathrm{E}_{2}$ and relaxin are known to induce robust VEGF expression in the uterus and elsewhere [17]; c) cytokines are expressed in the uterine cervix during pregnancy and following bacterial infection, and we have shown that Lipopolysaccharide (LPS) promotes mRNA expression of VEGF and its receptors [14]; d) if the robust growth of the uterine cervix, particularly in the last half of pregnancy, outgrows the micro vascular network, as maybe the case in cancer, it will lead to hypoxia, which is the most potent inducer of VEGF expression $[17,19]$.

In the present study, we examine: a) the effects of mimicking hypoxia and administering exogenous $\mathrm{E}_{2}$ on the expression pattern of VEGF and its receptors, VEGFR-2 and Flt-1, b) details of the expression pattern and identity of cell types expressing VEGF and its receptors in mice (pregnant and non-pregnant) and human (non-pregnant) uterine cervix.

\section{Materials and Methods}

\section{Subjects used in the study}

Mice: Non-pregnant (ovariectomized and treated) and timed-pregnant (days 11 and 17, untreated) female C57BL6/129SvEv mice, purchased from Charles Rivers, were used in the present studies. All experimental procedures were pre-approved and performed in accordance with the Guide for the Care and Use of Laboratory Animals of the local institution (Appalachian State University; IACUC Reference \#, 10-10) and the NIH guidelines (NIH publication number 86-23). All efforts were made to minimize the number of animals used and discomfort or suffering of the animals.

Humans: Human uterine cervical tissues from four non-pregnant women (Sheffield, England), were also used in the present study. All procedures were pre-approved by the local IRB of both institutions (IRB \#, 09-0002). The tissue samples were obtained using cervical punch biopsies during abdominal hysterectomy of benign pathologies (Table 1). These tissues were harvested, fixed in 10\% Formalin, processed and embedded in paraffin blocks using established standard procedures by our collaborator, Dr. Dilly Anumba (Sheffield University Medical School, Sheffield, England). We then cut 5 $\mathrm{mm}$ thick paraffin sections and stained them using standard Hematoxylin and Eosin (H \& E) stain and by confocal immunofluorescence, as described later.

\section{Animal surgeries, treatments and tissue harvest}

\section{Non-pregnant mice}

a). Surgeries (Ovariectomy): Before treatment with exogenous $\mathrm{E}_{2}$ and mimicked hypoxia, non-pregnant mice were ovariectomized (ovary removal), in order to prevent the confounding effects of endogenous ovarian sex steroid hormones. Prior to surgery, animals were anaesthetized using a mixture of ketamine (43-129 mg/g body weight) and xylazine (8.6-26 $\mathrm{mg} / \mathrm{g}$ body weight), followed immediately after surgery by administration of Baytril ${ }^{\circ}$ antibiotic (Bayer, Leverkusen, Germany), to prevent post-surgery infections. Animals were then allowed to rest for seven days post-surgery, before performing the experiments, to allow complete excretion of residual ovarian sex steroid hormones, confirmed during tissue harvest as significant reduction in uterine size. Animals with normal uterine size, seven days after ovariectomy, were eliminated from the study.

b) Treatments: Non-pregnant ovariectomized mice were then treated with either cobalt chloride $\left(\mathrm{CoCl}_{2}\right)$ or exogenous sex steroid

\begin{tabular}{|c|c|c|c|c|}
\hline Patient Code & NP05 & NP06 & NP07 & NP08 \\
\hline Age & 35 & 40 & 44 & 41 \\
\hline Smoking status & No & No & No & Yes \\
\hline Last cervical smear in 5 years & Yes & Yes & Yes & Yes \\
\hline Last smear normal & Yes & Yes & Yes & Yes \\
\hline Menopausal symptoms & No & No & No & No \\
\hline Hysterectomy type & Total & Total & Total & Total \\
\hline \multicolumn{5}{|l|}{ Surgery indication } \\
\hline -Menorrhagia & Yes & Yes & Yes & Yes \\
\hline - Other benign pathologies & Yes & Yes & No & Yes \\
\hline Menstrual phase & S & M & $S$ & M \\
\hline Hormonal treatment, last 6 weeks & None & None & None & None \\
\hline Number, previous pregnancies & 3 & 2 & 1 & 1 \\
\hline Number, miscarriages & 1 & 0 & 0 & 0 \\
\hline Delivery type (Vaginal/caesarian) & C & $\mathrm{v}$ & C & v \\
\hline Vaginal infection, last 6 weeks & None & None & None & None \\
\hline
\end{tabular}

Table 1: Demographical and clinical characteristics of patients used in the uterine cervix study.

Uterine cervical tissues were harvested from four women, with self-reporting phases of menstrual cycle, immediately after total abdominal hysterectomy of benign pathologies. Harvested tissues were then fixed, processed and embedded in paraffin blocks and sections were cut and analyzed for histology and confocal immunofluorescence (source of tissues, generously provided by Dr. Dilly Anumba).

hormones (17 $\beta$ estradiol, $E_{2}$ ), to examine their impact on the expression of VEGF and its receptors, VEGFR-2 and Flt-1, in the uterine cervix, as described below:

i). Effect of $\mathrm{CoCl}_{2}$ on expression of VEGF and its receptors: Mice were treated with either vehicle only, i.e., $0.9 \%$ sodium chloride $\left(\mathrm{NaCl}_{2}\right)$ or cobalt chloride $\left(\mathrm{CoCl}_{2}\right)$ (mimicked hypoxia) $(300 \mu \mathrm{M} / \mathrm{kg}$ body weight, dissolved in $\mathrm{NaCl}_{2}$ ), in a time-dependent manner (30, 90 and $180 \mathrm{~min}$ ), in order to simulate hypoxia, as described previously [21]. $\mathrm{CoCl}_{2}$ solution was administered Intra-Peritoneally (IP) and Intra-Luminally via the Vagina (ILV) $(n=6)$.

ii) Effect of exogenous $E_{2}$ on expression of VEGF and its receptors: Mice were treated with either vehicle (sesame oil) only (negative control group) or exogenous $\mathrm{E}_{2}$ dissolved in sesame oil, dose dependently ( $8 \mathrm{mg}, 4 \mathrm{mg}$ and $2 \mathrm{mg} / \mathrm{kg}$ body weight, respectively, $\mathrm{n}=7$ ), administered via IP once daily for 4 days, as described in our previous study [22].

Pregnant mice: Expression of VEGF and its receptors: Untreated mice in early and late pregnancy (days 11 and 17 of gestation, respectively; $n=4$ ) were used to examine the normal cellular pattern of VEGF expression and its (VEGF) receptors.

Tissue harvest: Following the treatments (non-pregnant), both pregnant and non-pregnant mice were euthanized by administering a lethal injection of Sodium Pentobarbital (Sleepaway, Fort Dodge Laboratories Inc., Burlingame, CA) and perfused intra-cardially with $0.9 \% \mathrm{NaCl}_{2}$, in order to flash out blood cells from the tissues. Uterine cervical tissues were then carefully dissected out under a stereomicroscope to avoid harvesting parts of vaginal and or uterine tissues. The tissues were then processed and analyzed accordingly. Tissues designated for Western blot analysis and real time Polymerase Chain Reaction (real time PCR) were snap frozen and immediately stored in $-80^{\circ} \mathrm{C}$ until at an appropriate time for processing. Tissues designated for morphological studies were fixed in $4 \%$ 
paraformaldehyde for at least 24 hours under $4^{\circ} \mathrm{C}$ and then dehydrated and processed using standard paraffin embedding procedures before storing under Room Temperature (RT) until sectioning.

\section{Techniques used in the study}

a) Basic Morphological Studies (H \& E staining): Experiments were undertaken to examine the basic histology of uterine tissues from mice (non-pregnant and pregnant) and human uterine cervix, as described here. Formalin (10\%) Fixed, Paraffin Embedded Tissues (FFPE) were cut into $5 \mu \mathrm{m}$ thick sections and stained with standard $\mathrm{H}$ \& E staining procedure (VWR international LLC, USA) and imaged using Olympus DSU IX81 (Olympus, USA) (Data not shown).

b) Protein Expression Studies: Cellular localization and tissue quantification of VEGF and VEGFRs protein expressions were studied using confocal immunofluorescence and Western blot analysis, respectively, as described below. Hypoxia Inducible Factor- $\alpha$ (HIF- $\alpha$ ), which is stabilized following $\mathrm{CoCl}_{2}$ treatment, was used as a positive control protein for hypoxia mimicking studies:

i). Confocal immunofluorescence: Briefly, paraffin sections were processed and incubated with primary antibodies, as described by our previous studies and the manufacturer [2] (Santa Cruz Biotechnology, Santa Cruz, CA) and sections (mice and human) were then incubated with 10\% Normal Goat Serum (NGS) (Vector laboratories Inc, USA), in order to block non-specific binding, before incubating with appropriate primary antibodies at $0.5 \mu \mathrm{g} / \mathrm{ml}$ (VEGF 164, Flt-1 and VEGF-2). Control sections were incubated with $10 \%$ NGS only, without primary antibodies. All sections were incubated with fluorescence-tagged secondary antibodies at $0.5 \mu \mathrm{g} / \mathrm{ml}$ for an hour, and after washes the nucleic acid was counterstained with $5 \mu \mathrm{M}$ Sytox ${ }^{\circ}$ Green before viewing images with confocal microscope (Zeiss LSM510, Thornwood, NY).

ii) Western Blot Analysis: Quantitative analysis of protein expression was performed to supplement confocal immunofluorescence data, as described below. Total protein was isolated from previously harvested frozen tissues using standard protein isolation protocol. After determining the concentrations of the isolated protein samples (Thermo Scientific, USA), $10 \mu \mathrm{g}$ of each protein sample was run on gel electrophoresis and the proteins were then transferred to PVDF membrane and incubated in blotto (5.0 g non-fat dry milk and 100 $\mathrm{ml}$ of $1 \mathrm{X}$ TBST) at $4^{\circ} \mathrm{C}$ before staining membranes with specific primary antibodies, as previously described $[2,13,16]$, prior to incubation with secondary antibody, i.e., Donkey anti-rabbit IgG HRP conjugated and Streptactin HRP antibodies for 1 hour at RT. After washes, membranes were then incubated with luminescenceproducing enzyme (limunol-enchancer/peroxidase solution), developed, imaged and analyzed with ImageJ program (NIH). The specific bands of the proteins of interest were identified using a standard ladder with known molecular weight.

c) Gene Expression Studies: Gene expression analysis was performed using real time PCR to examine the effects of $E_{2}$ and mimicked hypoxia on the mRNA expression of VEGF, VEGFRs and HIF- $\alpha$ in the uterine cervix of non-pregnant mice. Gene expression analysis was performed in three steps, as described in our previous studies $[13,16]$.

i) Tissue processing, total RNA isolation and quantification: Total RNA was isolated using the RNeasy Mini Kit (Qiagen, Valencia, $\mathrm{CA}$ ) and the quality and quantity of the samples were determined by Nanodrop Spectrophotometer (ND-2000, Thermo Scientific, USA).
Total RNA was diluted in RNase-free deionized (DI) water, stored at $-80^{\circ} \mathrm{C}$ until processed for Reverse Transcriptase PCR (RT-PCR), as described below.

ii) Reverse Transcriptase PCR (RT-PCR): Total RNA was reverse-transcribed and amplified in an Eppendorf Thermocycler (Hamburg, Germany) using reagents and protocol from the manufacturer (Applied Biosystems, Foster, CA). Briefly, to generate complementary DNA (cDNA), $1.0 \mu \mathrm{g}$ of previously isolated total RNA was brought to a total volume of $9.5 \mu \mathrm{L}$ per sample with RNase -free water, incubated in a water bath and at RT before adding $9.5 \mu \mathrm{L}$ of reverse transcriptase master mix to each tube, comprised of: reverse transcriptase buffer $(2 \mu \mathrm{L}$ per tube of RNA; Applied Biosystems, Foster, CA); Magnesium chloride $\left(\mathrm{MgCl}_{2}\right)(2 \mu \mathrm{L}$ per tube of RNA; Applied Biosystems, Foster, CA), dNTP $(2 \mu \mathrm{L}$ per tube of RNA; Applied Biosystems, Foster, CA); RNase inhibitor ( $0.5 \mu \mathrm{L}$ per tube of RNA; Applied Biosystems, Foster, CA); RNAse free water ( $2 \mu \mathrm{L}$ per tube of RNA; Applied Biosystems, Foster, CA); and random hexamers ( $1 \mu \mathrm{L}$ per tube of RNA; Applied Biosystems, Foster, CA). Lastly, $1.0 \mu \mathrm{L}$ of MuLV reverse transcriptase (Applied Biosystems, Foster, CA) was added to each tube, and the tube lacking reverse transcriptase enzyme served as a Non-Template Control (NTC) for DNA contamination. The Thermocycler was programmed accordingly to generate total cDNA, which was then used to evaluate mRNA levels of the genes of interest, as described in our previously published studies $[13,16]$.

iii) Real-time PCR: Relative expressions of VEGF, VEGFR-2 and Flt-1 were evaluated using real time PCR. DNA amplifications of the genes of interest were performed using the Applied Biosystems real time-PCR machine (ABI $7300 \mathrm{HT}$ ) with the GeneAmp $7300 \mathrm{HT}$ sequence detection system software (Perkin-Elmer Corp), assays and protocol provided by the manufacturer (Applied Biosystems, Foster, CA). Briefly, TaqMan ${ }^{\circ}$ Gene Expression Assays, which are pre-designed and pre-optimized gene-specific probe sets, were utilized and PCR reactions were set up in wells of 96-well plates in a volume of $25 \mu \mathrm{L}$ per well. The reaction components comprised of: 1.0 $\mu \mathrm{g} / 5.0 \mu \mathrm{L}$ of previously synthesized cDNA, $12.5 \mu \mathrm{L}$ of $2 \mathrm{X}$ Taqman ${ }^{\circ}$ Universal PCR Master Mix, $1.25 \mu \mathrm{L}$ of $20 \mathrm{X}$ Assays-on-Demand TM Gene Mix (e.g. VEGF), and $6.25 \mu \mathrm{L}$ of real time PCR-grade RNAse-free water. The program was set appropriately, as previously described $[13,16]$ and the relative expression of the genes of interest were calculated from the threshold cycles with the instrument's software (SDS 2.0) (Applied Biosystems, USA) and normalized against Gus $\beta$, accordingly to the manufacturer's instructions.

\section{Statistical analysis}

Data were analyzed using Student's t-test and ANOVA, followed by Scheffe's F-test for multiple comparisons. P-values of $<0.05$ were considered to be statistically significant.

\section{Results}

\section{Hypoxia simulation tends to regulate $m R N A$ and protein expression of VEGF and its receptors in the uterine cervix of mice:}

Changes in expression of HIF- $\alpha$, VEGF and VEGFRs mRNA and protein in uterine cervix of Non-Pregnant (NP) mice: i) Western blot: Levels of HIF-1 $\alpha$, which was used as a positive control protein to determine whether hypoxia was successfully simulated, were up-regulated in a time-dependent manner, following the treatment of the animals with $\mathrm{CoCl}_{2}$ (Figure $1 \mathrm{~A} ; \mathrm{p}<0.03 ; \mathrm{p}<0.026$ ), indicating 
Citation: Ohashi T, Anumba D, Mowa CN (2014) VEGF and its Receptors in Uterine Cervix: Dose-dependent Modulation by Hypoxia and Estrogen and Cellular Localization in Human. J Cytol Tissue Biol 1: 006.

the effectiveness of $\mathrm{CoCl}_{2}$ in simulating hypoxia. However, VEGF expression was just the opposite of $\mathrm{HIFa}$, i.e., it was down regulated time-dependently (Figure $1 \mathrm{~B} ; \mathrm{p}<0.00261$ ). Overall, although Flt-1 protein expression appears to increase, it was not found to be statistically significant (Figure 1C-D). Expression of VEGFR2 protein was not affected by $\operatorname{cocl}_{2}$.

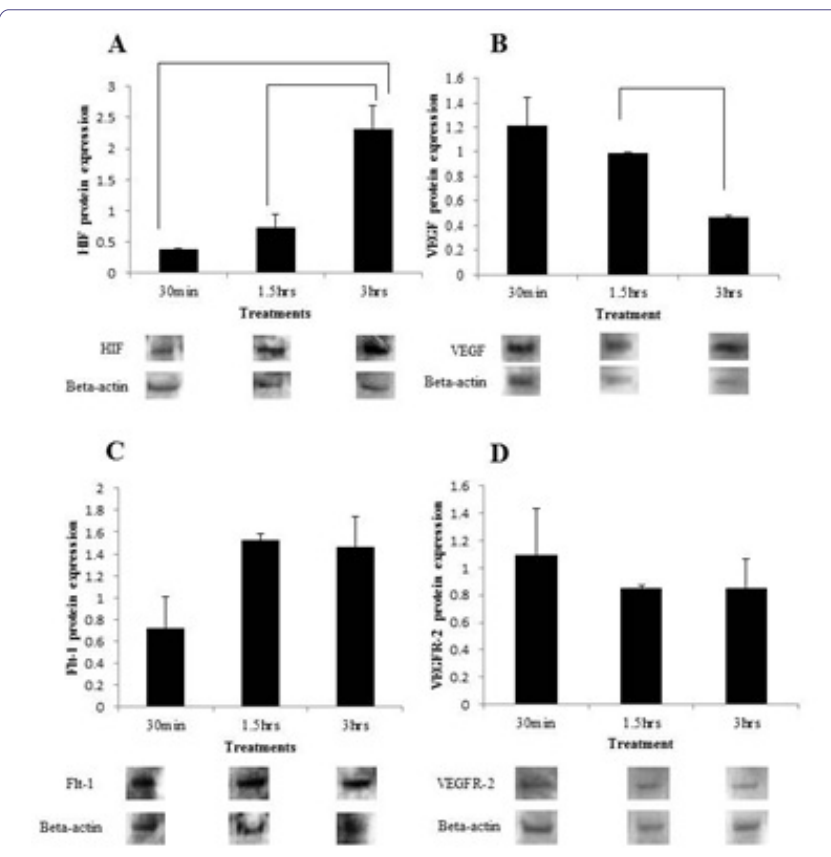

Figure 1: Effects of cobalt chloride $\left(\mathrm{CoCl}_{2}\right)$ on expression of HIF-a, VEGF, FIt-1 and VEGFR-2 proteins in the uterine cervix of non-pregnant mice, as revealed by Western Blot analysis.

Mice were either treated with $\mathrm{CoCl}_{2}(300 \mu \mathrm{M} / \mathrm{kg}$ body weight) for 30 min, 1.5 hours and 3 hours, respectively. After treatment with $\mathrm{CoCl}_{2}$, the intensity in HIF- $\alpha$ (A) protein expression increased time-dependently $\left({ }^{*}=p<0.03 ;{ }^{* *}=p<0.026\right)$, while that of VEGF $(B)$ was the opposite, i.e., decreased time-dependently $\left({ }^{*}=p<0.00261\right)$. Flt-1 expression tended to increase with time but was not statistically significant. No difference in expression for VEGFR-2 was noted (D). $n=6$.

ii) Confocal immunofluorescence: Data generated from confocal immunofluorescence were used to supplement the (data) obtained by Western blot analysis. The intensity of VEGF expression was found to be more pronounced at 3 hours post $\mathrm{CoCl}_{2}$ administration compared to the negative control group (Figure 2A-B). Similarly, the intensity of Flt-1 expression was much greater at 3 hours post $\mathrm{CoCl}_{2}$ administration compared to the negative control group (Figure 2C-D). However, VEGF expression here was inconsistent with Western blot analysis, showing difference between the Control versus the 30 min group, but not between the Control versus 3 hours treatment groups (Figure 2). No significant differences were observed between the negative control group and 3 hours post $\mathrm{CoCl}_{2}$ administration for VEGFR-2 expression, consistent with the data generated from Western blot (Figure 2E-F).

iii) Real time PCR: Messenger RNA expression of the positive control gene, HIF-1a, was, surprisingly, down-regulated immediately after administration of $\mathrm{CoCl}_{2}$ (Figure 3A). However, expression of the VEGF gene was up regulated, with the greatest levels achieved by 3 hours post $\mathrm{CoCl}_{2}$ administration (Figure 3B). Similarly, Flt-1 gene expression was also greatest at 3 hours post $\mathrm{CoCl}_{2}$ administration (Figure 3C). On the other hand, the gene expression of VEGFR-2 was down-regulated time-dependently (Figure 3D).

\section{Expression pattern of VEGF and its receptors change} during pregnancy in uterine cervix of mice:

Data generated from Western blot analysis shows increase in levels of both VEGF and its receptors (Flt-1 and VEGFR-2) in late (day 17) compared to early (day 11) pregnancy (Figure 4A-C).

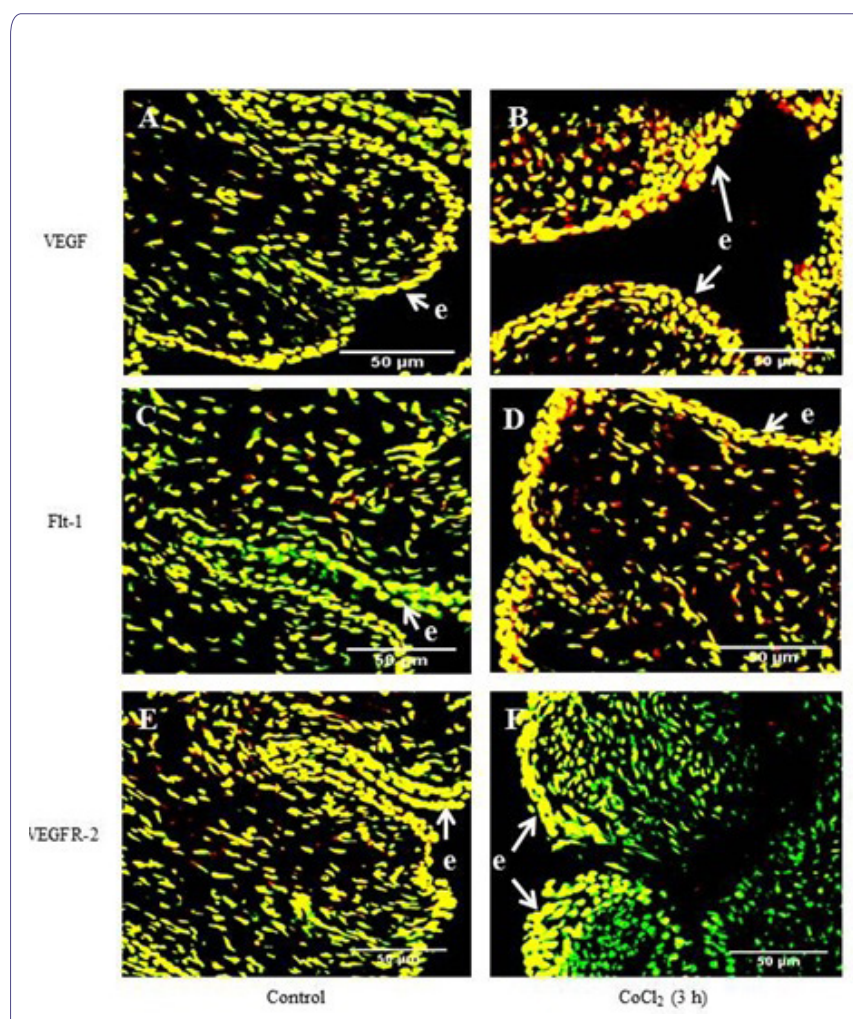

Figure 2: Effects of $\mathrm{CoCl}_{2}$ on expression of VEGF, FIt-1 and VEGFR-2 proteins in the mice cervix, as revealed by confocal immunofluorescence.

Uterine cervices of mice treated with $\mathrm{CoCl}_{2}$ were immuno-stained with different primary antibodies of target proteins (red fluorescence) and counterstained with Sytox $®$ Green, which is displayed as green fluorescence in the cellular nuclei. Images on the left column (A, C, E, x40) were from $0.9 \% \mathrm{NaCl}_{2}$ only-treated animals (negative control group) and those on the right column were from $\mathrm{CoCl}_{2}$-treated animals (B, D, F, x40), i.e., 3h $(300 \mu \mathrm{M} /$ $\mathrm{kg}$ body weight), and not 30 min or 1.5 hours. $\mathrm{CoCl}_{2}$ treatment induced a more pronounced expression of the target proteins (VEGF: Figures $2 \mathrm{~A}$ vs. B; Flt-1: Figures $2 \mathrm{C}$ vs. D), in both stromal and epithelial cells (e=epithelia; $\mathrm{red} / \mathrm{yellow}=$ cells with positive protein expressions; green=cellular nucleic), compared to control, except for VEGFR-2, showing no difference with 3 hours. $\mathrm{n}=6$.

\section{$E_{2}$ regulates expression of VEGF and its receptors in mice} cervix:

i) Western blot: Data generated from Western blot shows that $E_{2}$ tended to up regulate the protein levels of VEGF and Flt-1 in a dose-dependent manner (Figure 5A-B), but not VEGFR-2, which, on the contrary, was found not to vary (Figure $5 \mathrm{C}$ ).

ii) Confocal immunofluorescence studies were designed to identify specific cell types expressing the proteins of interest and complement data generated from Western blot analysis. VEGF expressions in the negative control group were largely localized in the epithelial and just below it, i.e., sub-epithelial compartments (Figure 6A). Cellular localization of VEGF in $\mathrm{E}_{2}$-treated animals was more widespread, beyond the epithelial and sub-epithelial compartments, and 


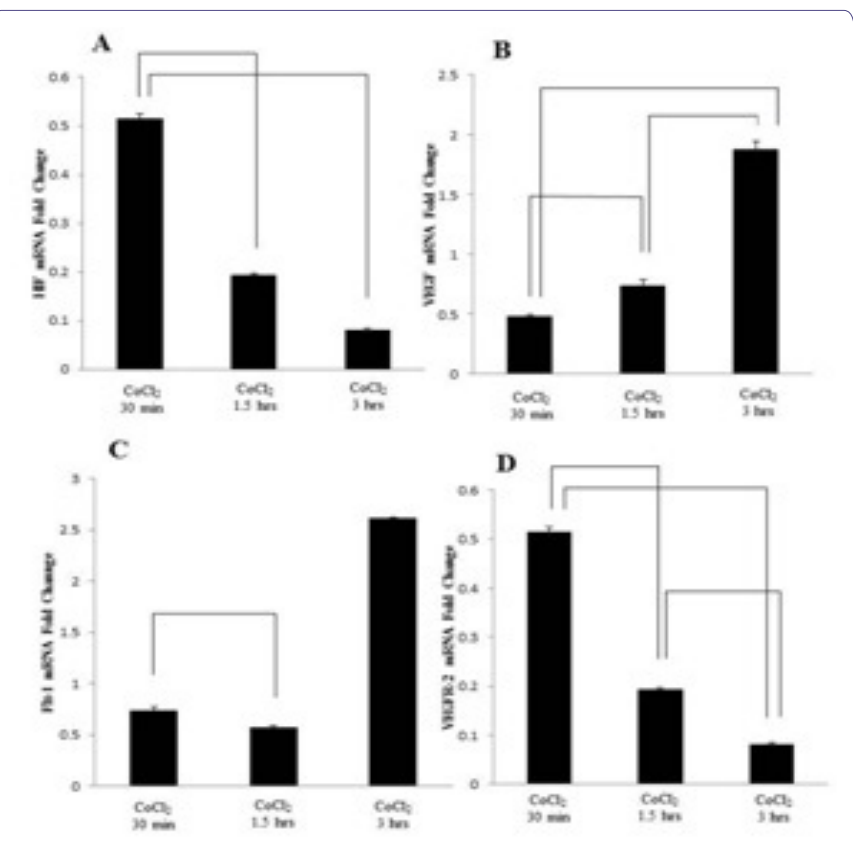

Figure 3: Effects of $\mathrm{CoCl}_{2}$ on mRNA expression of HIFa, VEGF, Flt-1 and VEGFR-2 in the uterine cervix of non-pregnant mice, as revealed by real-time PCR.

Treatment of mice with $\mathrm{CoCl} 2(300 \mu \mathrm{M} / \mathrm{kg})$ for $30 \mathrm{~min}, 1.5$ hours and 3 hours, respectively, increased mRNA expression of VEGF $(B)\left({ }^{*} \mathrm{p}<0.0053\right.$; $\left.{ }^{* *} p<0.00056 ;{ }^{* *} p<0.000079\right)$ and Flt-1 (C) $\left({ }^{*} p=0.0030\right)$, while it decreased levels of HIF- $\alpha(A)\left({ }^{*} p<0.0056 ;{ }^{* *} p<0.0026\right)$, as well as VEGFR-2 $\left({ }^{*} p<0.0052\right.$; $\left.{ }^{* *} p<0.0000657 ;{ }^{* * *} p<0.00015\right)$, in the uterine cervix, in a time-dependent fashion. $\mathrm{n}=6$.
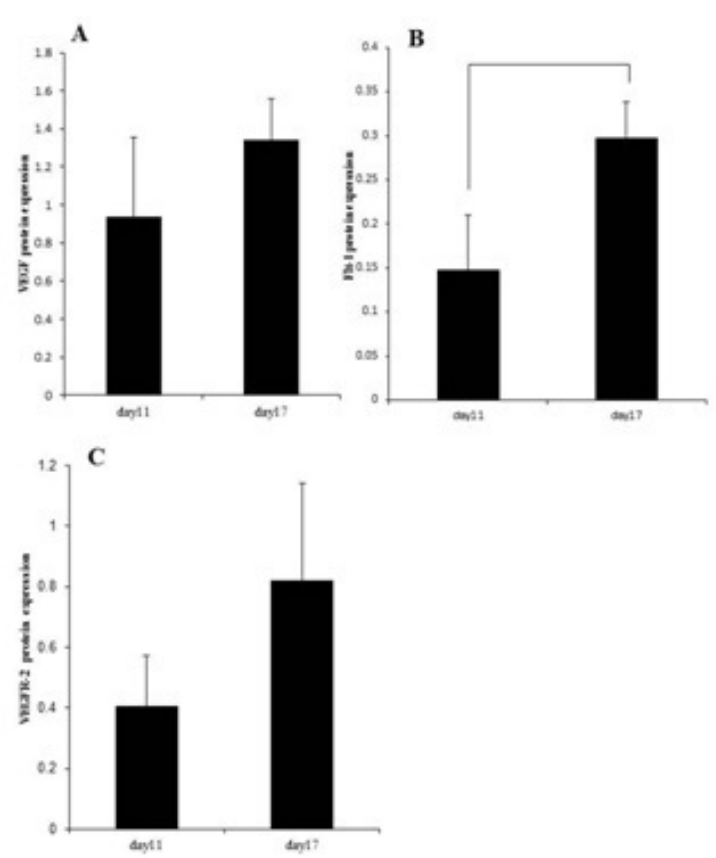

Figure 4: Expression profile of VEGF, FIt-1 and VEGFR-2 proteins in the uterine cervix of pregnant mice, as revealed by Western Blot analysis.

Expression of all the proteins of interest (VEGF, Flt-1 and VEGFR-2) increased during early (day 11) and late (day 17) pregnancy. However, only the expression of Flt-1 (B) was found to be statistically significant $\left({ }^{*} p<0.03048\right)$, but not the other two proteins VEGF (A); Flt-1 (B). $n=3$. included stromal cells and was up regulated by exogenous $\mathrm{E}_{2}$, in a dose-dependent manner (Figure 6B). Flt-1 expression was visually noted by confocal immunofluorescence in both the negative control group and $\mathrm{E}_{2}$-treated uterine cervices. Intensity of Flt-1 expression was more pronounced in $\mathrm{E}_{2}$-treated mice, particularly near and on the epithelia (Figure 6D). Minimal differences in VEGFR-2 expression were observed between the negative control group and $\mathrm{E}_{2}$-treated mice (Figure 6E-F).

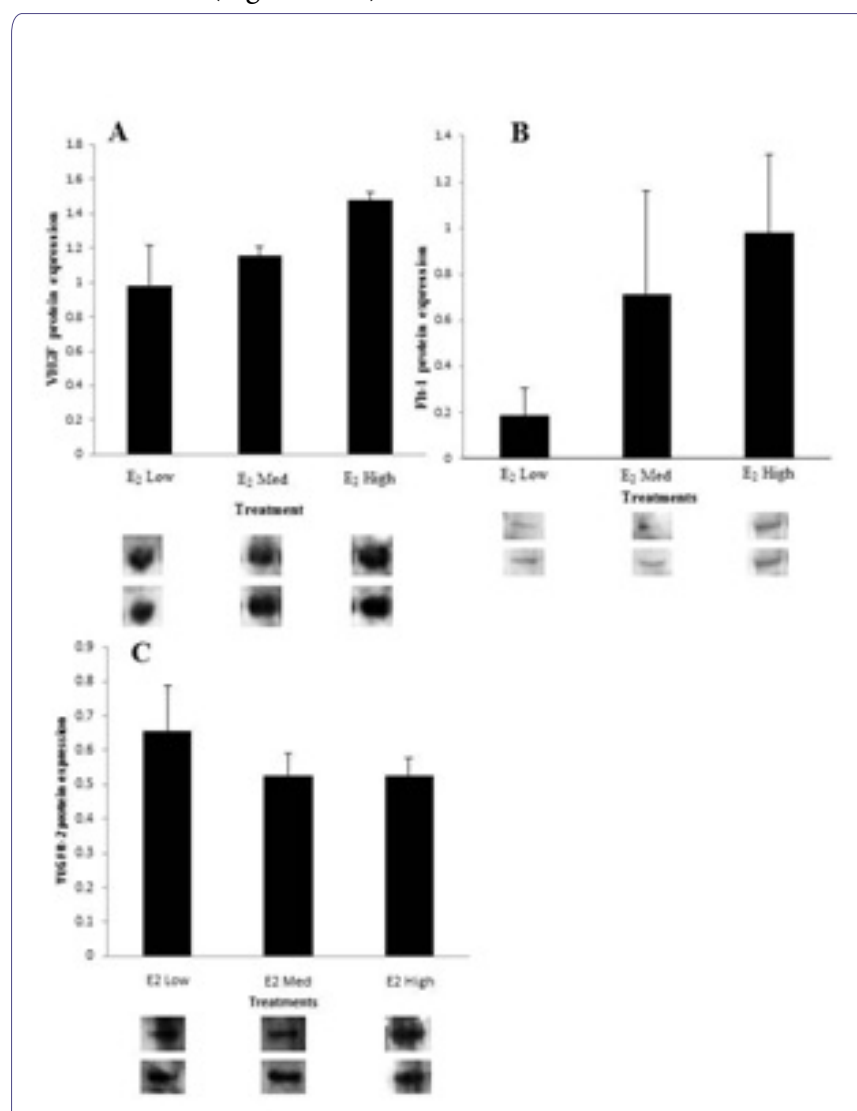

Figure 5: Effects of 17ß-estradiol on expression of VEGF, VEGFR-2 and FIt-1 proteins in the uterine cervix of non-pregnant mice, as revealed by Western Blot.

Although the exogenous $E_{2}$ treatment tended to induce expression of all the proteins of interest [VEGF (A), Flt-1 (B)] dose-dependently $(2 \mathrm{mg}, 4 \mathrm{mg}$ and 8 $\mathrm{mg} / \mathrm{kg}$ body weight), except for VEGFR-2 (C), no expression was found to be of any statistical significance in uterine cervical tissue of mice. $n=4$.

\section{VEGF and its receptors are expressed in the uterine cervix of non-pregnant women:}

Data generated from confocal immunofluorescence of human uterine cervix shows presence of VEGF and its receptors (Figure 7A-C). All the three proteins of interest were found to be expressed intensely. However, there were variations in both the intensity of expression and cellular localization between the subjects, who were in different self-reported phases of the menstrual cycle. For instance, expression of VEGF was most intense in subject NPO8 and was largely localized in apparent stromal cells (Figure 7A), whereas, expression of Flt-1 and VEGFR-2 were both expressed in all the women, but their cellular localization was largely confined to epithelial cells (Figure 7B-C). These patterns of cellular localization 
of VEGF and its receptors in human uterine cervix were comparable to the uterine cervix of ovariectomized non-pregnant mice (Figure 7D-F).
VEGF

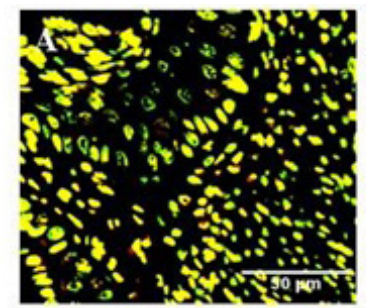

Fit-1
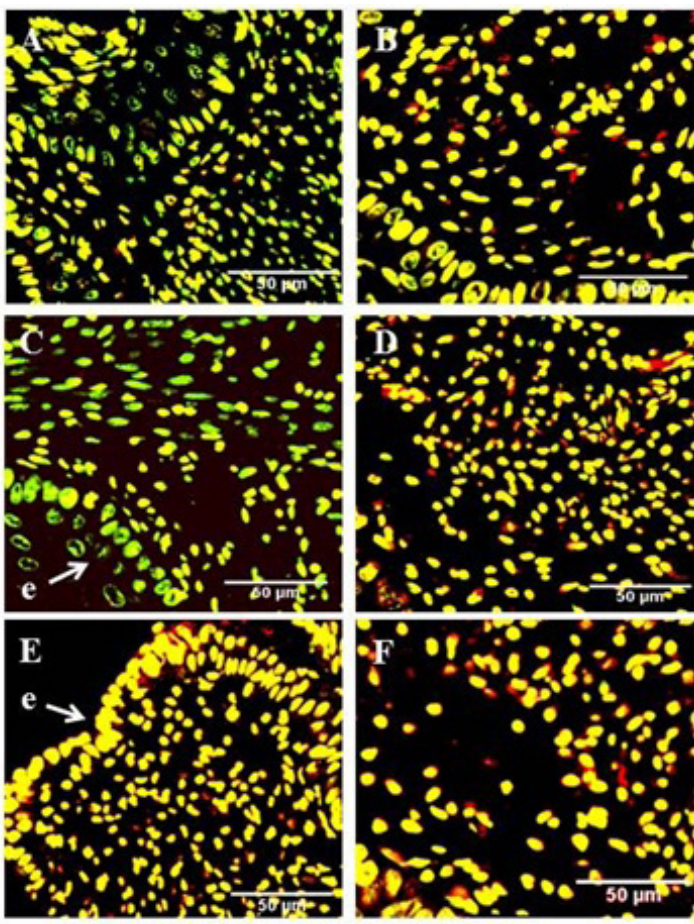

Control

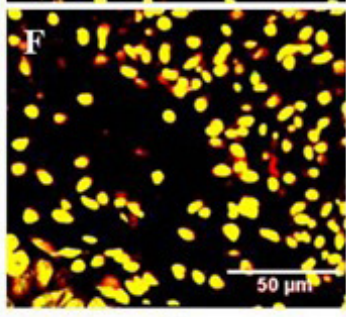

Figure 6: Effects of $17 \beta$-estradiol on expression of VEGF, Flt-1 and VEGFR-2 proteins in the mice uterine cervix, as revealed by confocal immunofluorescence.

Uterine cervices of mice treated with $E_{2}$ were immuno-stained with different primary antibodies of target proteins (red fluorescence) and counterstained with Sytox ${ }^{\circledR}$ Green, which is displayed as green fluorescence in the cellular nuclei. Exogenous $E_{2}$ appeared to increase protein expression of VEGF (A) and its receptors (FIt-1, B) but not VEGFR-2 (C) $(8 \mathrm{mg} / \mathrm{kg}$ body weight) in uterine cervical tissue of mice. Images on the right column $(B, D, F)$ are from animals treated with $E_{2}$ and those on the left column $(A, C, E)$ are from the negative control group (sesame oil only). e=epithelia; red/yellow=cells with positive protein expressions; green=cellular nucleic. $n=7$.

\section{Discussion}

The human female reproductive tissues undergo marked changes during gestation and monthly menstrual cycles. Supporting and sustaining these tissue changes require an equally dynamic vascular network that ensures access to essential resources and removal of toxins and metabolic waste products from cells [23]. VEGF is the best characterized angiogenic regulator and is the key architect of the vascular network. Our prior studies have characterized the presence and the expression profile of VEGF and its receptors in the uterine cervix of pregnant rodents over the course of pregnancy [24-26]. However, the factors that induce expression of endogenous VEGF and its receptors in the uterine cervix are not completely known. We do know in other tissues that hypoxia, acting through HIF-1 $\alpha$, is the most potent inducer of VEGF [27] and that sex steroid hormones, such as $\mathrm{E}_{2}$, in the uterus, induces VEGF expression [28]. Further, recent studies in the uterus have revealed complex molecular and signaling interplay between $\mathrm{E}_{2}$ and hypoxia in the induction of VEGF expression. Here, 1) in mice, we: a) reveal the cellular pattern of VEGF expression and its receptors (Flt-1 and VEGFR-2) and $\mathbf{b}$ ) show that hypoxia and $E_{2}$ variably induce mRNA and protein expression of

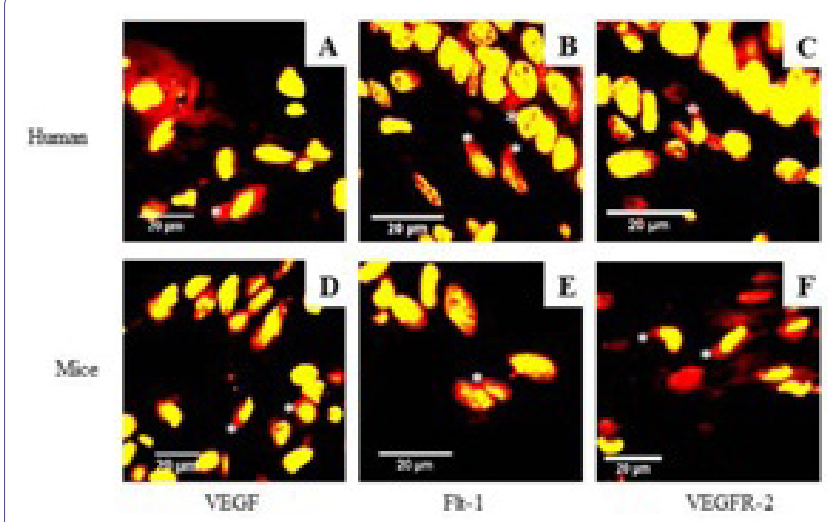

Figure 7: VEGF and VEGFRs protein expressions in the uterine cervix of human

Confocal immunofluorescence of VEGF and its receptors (Flt-1 and VEGFR-2) were localized in the uterine cervical stromal and epithelia cells (top right, "B" and "C") of non-pregnant human (Top row, A-C). Red/yellow=cells with positive protein expressions; green=cellular nucleic staining.

HIF- $\alpha$, VEGF and VEGFRs molecules in the uterine cervix; and 2) in human, we also demonstrate that the uterine cervix express VEGF and its receptors (Flt-1 and VEGFR-2). Collectively, these data shed new insights into the regulation and pattern of VEGF expression in the uterine cervix of rodents and human.

Local tissue oxygen tension is tightly regulated, as it plays a critical role in tissue survival and function, under normal physiological conditions. Tissue oxygen levels below normal (normoxia, i.e., $3 \%$ ) lead to hypoxia and, consequently, an increase in the concentration of a hypoxia-associated transcription factor, HIF-1a, which is degraded rapidly in normoxic conditions, where tissue oxygen levels are equal or greater than $3 \%$. HIF-1a regulates expression of more than 100 genes, including those that are not associated with hypoxia under hypoxia-independent stimuli, such as estrogen (see below). The von Hippel-Lindau protein (pVHL) mediates the ubiquitination and rapid degradation of HIF- $\alpha$ (including HIF- $1 \alpha$ and $-2 \alpha$ ), but not HIF- $1 \beta$, which is constitutively expressed under normoxic conditions. The critical step prior to interaction between HIF and pVHL, is a post-translational hydroxylation of a proline residue in the Oxygen-Dependent Degradation (ODD) domain of HIF- $\alpha$.

$\mathrm{CoCl}_{2}$ mimics hypoxia by either blocking the activity of the enzyme that hydroxylates the proline residue in the ODD, Prolyl Hydroxylase Domain-containing enzymes (PHDs), which is a family of enzymes that play a key role in oxygen-dependent degradation of the transcription factor [29] and or by inhibiting the binding of pVHL to HIF- $\alpha$, even when HIF- $\alpha$ is hydroxylated [30,31]. The effectiveness of $\mathrm{CoCl}_{2}$ in the present study is shown by a time-dependent accumulation of HIF-1 $\alpha$ protein and increase in expression of VEGF. However, we are not completely sure of the specific cell type, as we did not immunostain these cells with specific endothelial cell markers, such as vWF. Because the uterine cervix undergoes marked growth over the course of pregnancy, especially in the last $2 / 3^{\text {rd }}$ of pregnancy and our previous study showed increase in vWF immunoreactivity in the cervix of rat during pregnancy [2], such pronounced growth is likely to induce hypoxia and, consequently, accumulation of HIF- $1 \alpha$ and expression of VEGF. However, although HIF- $\alpha$ protein was induced by hypoxia, mRNA expression was, surprisingly down 
regulated time-dependently. This observation implies that the mRNA may have been degraded by 15-3.0 hours post $\mathrm{CoCl}_{2}$ treatment, perhaps reflecting increase in levels of VEGF induction by that time. We do know that hypoxia is generally induced during significant tissue growth or under the influence of growth promoters, such as estrogen and relaxin. For instance, in tumor, when the tissue reaches a size of about $0.2-2.0 \mathrm{~mm}$ in diameter, without an equivalent change in blood supply, hypoxia is induced, which will then turn on the angiogenic "switch" via induction of HIF-1a [32]. Indeed, our previous studies show a close temporal relationship between expression of VEGF/receptors and gestational age [28], and a recent study induced hypoxia and VEGF expression and examined the effects of hypoxia on the biomechanical properties of the rat uterine cervix, using a chamber. Moreover, it is interesting to note that women in Peru, when close to their due date, can intentionally induce the birth process by going to higher altitudes, where oxygen levels are low or conditions are relatively hypoxic [33]. However, more studies are needed to characterize the role of HIF-1a in pregnancy, and decipher the molecular mechanisms and pathways that mediate these biological effects in the uterine cervix under physiological and aberrant conditions, such as preterm labor.

Sex steroid hormones, including $\mathrm{E}_{2}$, are known to differentially alter the expression of VEGF and its receptors in a variety of tissues [34-47]. While $E_{2}$ promotes expression of VEGF in the uterus and mammary tumors in the female rats [40], regulation of VEGF by $\mathrm{E}_{2}$ in some tissues is much more complex and appears to be context-dependent. For instance, whereas, $\mathrm{E}_{2}$ induces VEGF gene expression in Ishikawa and MCF-7 breast cancer cells [42,44,47], it $\left(\mathrm{E}_{2}\right)$ decreases VEGF gene expression in HEC1A endometrial cancer cell lines, even though they are also Estrogen Receptor (ER)-positive [45]. Although ER and VEGF and its receptors have been described previously in the uterine cervix and appear to have a temporal relationship, until now, very little was known whether there was a cause-and-effect relationship between the two factors. Here, we have shown that modulation of VEGF mRNA and protein by exogenous $\mathrm{E}_{2}$ in the uterine cervix is rather complex. Our present findings correlate with studies that used rodent uterus, Ishikawa and MCF-7 breast cancer cells, as cited above $[42,44,47]$.

For now, it is not clear exactly how $\mathrm{E}_{2}$ alters expression of VEGF and its receptors in the uterine cervix and how this relates to uterine cervical events, notably CR. It is, however, intriguing to note some striking similarities and overlap between the biological effects of VEGF with another $E_{2}$ responsive gene whose actions on the uterine cervix have been extensively characterized, namely relaxin. Both relaxin and VEGF: $\mathbf{a}$ ) are responsive to $\mathrm{E}_{2} ; \mathbf{b}$ ) induce proliferation of uterine cervical epithelial cells and expression of endothelial Nitric Oxide Synthase (eNOS) in the uterus, dose-dependently $[17,48,49]$; c) reduce tissue tensile strength in rodents and; d) exert similar vascular effects (normal and aberrant), such as vasodilation [50,51]. For instance, in women with scleroderma administered continuously subcutaneous infusion of relaxin over 24 weeks, relaxin mimics typical VEGF-like vascular physiological effects, described in human pregnancy, particularly increased blood volume, flow and angiogenesis [52]. Notable side effects reported included hyper-menorrhagia (excess bleeding), which is likely due to abnormal vascular permeability or vessel leakage, another signature characteristic of aberrant VEGF concentration [52]. Lastly, a recent report concluded that the primary role of relaxin mainly involves regulation of body fluids and circulation hemostasis, roles that are comparable to VEGF action [49].
We conclude that levels of VEGF and its receptors are altered by hypoxia simulation and exogenous $\mathrm{E}_{2}$ in a complex and varied manner in the mice; are present and variably expressed in the uterine cervix of non-pregnant women and that they are synthesized by multiple cell types of both mice and human uterine cervix. These findings may shed new insights into deciphering the role of VEGF and its underlying mechanism in CR, as it relates to pre-term labor, an obstetrical problem affecting both mothers and babies.

\section{References}

1. Downing SJ, Sherwood OD (1985) The physiological role of relaxin in the pregnant rat. III. The influence of relaxin on cervical extensibility. Endocrinology 116: $1215-1220$.

2. Mowa CN, Jesmin S, Sakuma I, Usip S, Togashi H, et al. (2004) Characterization of Vascular Endothelial Growth Factor (VEGF) in the uterine cervix over pregnancy: effects of denervation and implications for cervical ripening. J Histochem Cytochem 52: 1665-1674.

3. Koos RD, Kazi AA, Roberson MS, Jones JM (2005) New insight into the transcriptional regulation of vascular endothelial growth factor expression in the endometrium by estrogen and relaxin. Ann N Y Acad Sci 1041: 233-247.

4. Shifren JL, Tseng JF, Zaloudek CJ, Ryan IP, Meng YG, et al. (1996) Ovarian steroid regulation of vascular endothelial growth factor in the human endometrium: implications for angiogenesis during the menstrual cycle and in the pathogenesis of endometriosis. J Clinc Endocrinol Metab, 81: 3112-3118.

5. Yan A, Avraham T, Zampell JC, Aschen SZ, Mehrara BJ (2011) Mechanisms of lymphatic regeneration after tissue transfer. PLoS One 6: e17201.

6. Ferrara N, Davis-Smyth T (1997) The biology of vascular endothelial growth factor. Endocr Rev 18: 4-25.

7. de Vries C, Escobedo JA, Ueno H, Houck K, Ferrara N, et al. (1992) The fms-like tyrosine kinase, a receptor for vascular endothelial growth factor. Science 255: 989-991.

8. Shibuya M Role of VEGF-FIt-1 receptor system in normal and tumor angiogenesis. Nature Med 1998, 4: 336-340.

9. Leppert PC, Yu SY (1994) Apoptosis in the cervix of pregnant rats in association with cervical softening. Gynecol Obstet Invest 37: 150-154.

10. Breeveld-Dwarkasing VN, te Koppele JM, Bank RA, van der Weijden GC Taverne MA, et al. (2003) Changes in water content, collagen degradation, collagen content, and concentration in repeated biopsies of the cervix of pregnant cows. Biol Reprod 69: 1608-1614.

11. Challis JRG (2000) Mechanism of parturition and preterm labor. Obstet Gynecol Surv 55: 650-660.

12. Ferrara N, Chen H, Davis-Smyth T, Gerber HP, Nguyen TN, et al. (1998) Vascular endothelial growth factor is essential for corpus luteum angiogenesis. Nat Med 4: 336-340.

13. Mowa CN, Li T, Jesmin S, Folkesson HG, Usip SE, et al. (2008) Delineation of VEGF-regulated genes and functions in the cervix of pregnant rodents by DNA microarray analysis. Reprod Biol Endocrinol 6: 64.

14. Dussably L, Buhimschii I, Sisi P, Li X, Weiner C, Gee H, Ahmed A (2003) Vascular Endothelial Growth Factor (VEGF) promotes cervical ripening, in vivo. J Soc Gynecol Investig s10.

15. Nguyen BT, Minkiewicz V, McCabe E, Cecile J, Mowa CN (2012) Vascular endothelial growth factor induces mRNA expression of pro-inflammatory factors in the uterine cervix of mice. Biomed Res 33: 363-372.

16. Donnelly SM, Nguyen BT, Rhyne S, Estes J, Jesmin S, et al. (2013) Vascular endothelial growth factor induces growth of uterine cervix and immune cell recruitment in mice. J Endocrinol 217: 83-94.

17. Unemori E, Erickson M, Rocco S, Sutherland K, Parsell D, et al. (1999) Relaxin stimulates expression of vascular endothelial growth factor in norma human endometrial cells in vitro and is associated with menometrorrhagia in women. Human Reprod 14: 800-806. 
Citation: Ohashi T, Anumba D, Mowa CN (2014) VEGF and its Receptors in Uterine Cervix: Dose-dependent Modulation by Hypoxia and Estrogen and Cellular Localization in Human. J Cytol Tissue Biol 1: 006.

18. Koos RD, Kazi AA, Roberson MS, Jones JM (2005) New insight into the transcriptional regulation of vascular endothelial growth factor expression in the endometrium by estrogen and relaxin. Ann N Y Acad Sci 1041: 233-247.

19. Taki A, Abe M, Komari M, Oku K, Iseki S, et al. (2012) Expression of angiogenesis-related factors and inflammatory cytokines in placenta and umbilical vessels in pregnancies with preeclampsia and chorioamnionitis/ funisitis. Congenit Anom (Kyoto) 52: 97-103.

20. Zhang P, Baxter J, Vinod K, Tulenko TN, Di Muzio PJ (2009) Endothelia differentiation of amniotic fluid-derived stem cells: synergism of biochemical and shear force stimuli. Stem Cells Dev 18: 1299-1308.

21. Matsumoto K, Fujishiro $H$, Satoh M, Himeno S (2010) DNA microarray analysis of the liver of mice treated with cobalt chloride. J Toxicol Sci 35: 935-939.

22. Mowa CN, Hoch R, Montavon CL, Jesmin S, Hindman G, et al. (2008) Estrogen enhances wound healing in the penis of rats. Biomed Res 29: 267-270.

23. Andersson S, Minjarez D, Yost NP, Word RA (2008) Estrogen and progesterone metabolism in the cervix during pregnancy and parturition. J Clin Endocrinol Metab 93: 2366-2374.

24. Sharma PS, Sharma R, Tyagi T (2011) VEGF/VEGFR pathway inhibitors as anti-angiogenic agents: present and future. Curr Cancer Drug Targets 11 624-653.

25. Shifren J, Tseng J, Zaloudek C, Ryan I, Meng Y, et al. (1996) Ovarian steroid regulation of vascular endothelial growth factor in the human endometrium: implications for angiogenesis during the menstrual cycle and in the pathogenesis of endometriosis. J Clinic Endocrinol Metab 81: 3112-3118.

26. Simon C, Einspanier A (2009) The hormonal induction of cervical remodeling in the common marmoset monkey (Callithrix jacchus). Reproduction 137 517-525.

27. Yao L, Cooke P, Meling D, Shanks R, Jameson L, et al. (2010) The effect of relaxin on cell proliferation in mouse cervix requires estrogen receptor a binding to estrogen response elements in stromal cells. Endocrinology 151 2811-2818.

28. Mowa C, Jesmin S, Sakuma I, Usip S, Togashi H, et al. (2004) Characterization of Vascular Endothelial Growth Factor (VEGF) in the uterine cervix over pregnancy: effects of denervation and implication for cervical ripening. $J$ Histochem Cytochem 52: 1665-1674.

29. Epstein AC, Gleadle JM, McNeill LA, Hewitson KS, O'Rourke J, et al. (2001) C. elegans EGL-9 and mammalian homologs define a family of dioxygenases that regulate HIF by prolyl hydroxylation. Cell 107: 43-54.

30. Ho VT, Bunn HF (1996) Effects of transition metals on the expression of the erythropoietin gene: further evidence that the oxygen sensor is a heme protein. Biochem Biophys Res Commun 223: 175-180.

31. Young Y, Hilliard G, Ferguson T, Millhorn DE (2003) Cobalt inhibits the interaction between hypoxia-inducible factor-alpha and von Hippel-Lindau protein by direct binding to hypoxia-inducible factor-alpha. J Biol Chem 278: 15911 15916.

32. Koh MY, Powis G (2012) Passing the baton: the HIF switch. Trends Biochem Sci 37: 364-372.

33. Bonney EA (2012) Are Inflammation and Oxidative Stress the Chicken and the Egg of Preterm Birth? [presentation] Society for Gynecologic Investigation. San Diego, CA, USA.

34. Stoner M, Wormkel M, Saville B, Samudio I, Qin C, et al. (2004) Safe S: Estrogen regulation of vascular endothelial growth factor gene expression in ZR-75 breast cancer cells through interaction of estrogen receptor a and PS proteins. Oncogene 23: 1052-1063
35. Cullinan-Bove K, Koos RD (1993) Vascular endothelial growth factor/vascular permeability factor expression in the rat uterus: rapid stimulation by estrogen correlates with estrogen-induced increases in uterine capillary permeability and growth. Endocrinology 133: 829-837.

36. Hyder SM, Stancel GM, Chiappetta C, Murthy L, Boettger-Tong HL, et al. (1996) Uterine expression of vascular endothelial growth factor is increased by estradiol and tamoxifen. Cancer Res 56: 3954-3960.

37. Hyder SM, Chiappetta C, Murthy L, Stancel GM (1997) Selective inhibition of estrogen-regulated gene expression in vivo by the pure antiestrogen $\mathrm{ICl}$ 182,780. Cancer Res 57: 2547-2549.

38. Hyder SM, Murthy L, Stancel GM (1998) Progestin regulation of vascular endothelial growth factor in human breast cancer cells. Cancer Res 58: 392395

39. Hyder SM, Nawaz Z, Chiappetta C, Stancel GM (2000) Identification of functional estrogen response elements in the gene coding for the potent angiogenic factor vascular endothelial growth factor. Cancer Res 60: 3183-3190.

40. Nakamura K, Ishida H, lizumi T (2000) Constitutive trichloroethylene degradation led by tac promoter chromosomally integrated upstream of phenol hydroxylase genes of Ralstonia sp. KN1 and its nucleotide sequence analysis. J Biosci Bioeng 89: 47-54.

41. Yoshigi M, Keller BB (1997) Characterization of embryonic aortic impedance with lumped parameter models. Am J Physiol 273: 19-27.

42. Ruohola JK, Valve EM, Karkkainen MJ, Joukov V, Alitalo K, et al. (1999) Vascular endothelial growth factors are differentially regulated by steroid hormones and antiestrogens in breast cancer cells. Mol Cell Endocrinol 149: $29-40$

43. Classen-Linke I, Alfer J, Krusche CA, Chwalisz K, Rath W, et al. (2000) Progestins, progesterone receptor modulators, and progesterone antagonists change VEGF release of endometrial cells in culture. Steroids 6: 763-771.

44. Mueller JD, Stein HJ, Oyang T, Natsugoe S, Feith M, et al. (2000) Frequency and clinical impact of lymph node micrometastasis and tumor cell microinvolvement in patients with adenocarcinoma of the esophagogastric junction. Cancer 89: 1874-1882.

45. Stoner M, Wang F, Wormke M, Nguyen T, Samudio I, et al. (2000) Inhibition of vascular endothelial growth factor expression in HEC1A endometrial cancer cells through interactions of estrogen receptor alpha and Sp3 proteins. J Biol Chem 275: 22769-22779.

46. Bogin L, Degani H (2002) Hormonal regulation of VEGF in orthotopic MCF7 human breast cancer. Cancer Res 62: 1948-1951.

47. Buteau-Lozano H, Ancelin M, Lardeux B, Milanini J, Perrot-Applanat M (2002) Transcriptional regulation of vascular endothelial growth factor by estradiol and tamoxifen in breast cancer cells: a complex interplay between estrogen receptors alpha and beta. Cancer Res 62: 4977-4984.

48. Bani-Sacchi T, Bigazzi M, Bani D, Mannaioni PF, Masini E (1995) Relaxin-induced increased coronary flow through stimulation of nitric oxide production. Br J Pharmacol 116: 1589-1594.

49. Dschietzig T, Stangl K (2003) Relaxin: a pregnancy hormone as central player of body fluid and circulation homeostasis. Cell Mol Life Sci 60: 688-700.

50. Bani G, Bigazzi M (1984) Morphological changes induced in mouse mammary gland by porcine and human relaxin. Acta Anat (Basel) 119: 149-154.

51. St-Louis J, Massicotte G (1985) Chronic decrease of blood pressure by rat relaxin in spontaneously hypertensive rats. Life Sci 37: 1351-1357.

52. Seibold JR (2002) Relaxins: lessons and limitations. Curr Rheumatol Rep 4 275-276 